\title{
MISSION, VALUES, AND VISION
}

\section{MISSION}

California State University, Northridge exists to enable students to realize their educational goals. The University's first priority is to promote the welfare and intellectual progress of students. To fulfill this mission, we design programs and activities to help students develop the academic competencies, professional skills, critical and creative abilities, and ethical values of learned persons who live in a democratic society, an interdependent world, and a technological age; we seek to foster a rigorous and contemporary understanding of the liberal arts, sciences, and professional disciplines, and we believe in the following values.

\section{VALUES}

Commitment to Teaching, Scholarship, and Active Learning. We demonstrate excellence in teaching.We honor and reward high performance in learning, teaching, scholarship, research, service, and creative activity. Because the quality of our academic programs is central to our mission, we encourage intellectual curiosity and protect the multiple expressions of academic freedom.

Commitment to Excellence. We set the highest standards for ourselves in all of our actions and activities and support the professional development of faculty, staff and administrators. We assess our performance so that every area of University life will be continually improved and renewed. We recognize and reward our efforts of greatest distinction and through them provide state and national leadership.

Respect for All People. We aspire to behave as an inclusive, cooperative community. Our behaviors, policies, and programs affirm the worth and personal dignity of every member of the University community and contribute to a campus climate of civility, collegiality, tolerance, and reasoned debate.

Alliances with the Community. We seek partnerships with local schools, community colleges, businesses, government and social agencies to advance the educational, intellectual, artistic, civic, cultural and economic aspirations of our surrounding communities.

Encouragement of Innovation, Experimentation, and Creativity. We seek to provide an environment conducive to innovation, experimentation, and creativity. We encourage all members of our community to take intellectual and creative risks and to embrace changes that will enhance the fulfillment of the University's mission.

\section{VISION}

California State University, Northridge is inspired by the belief that our commitment to educational opportunity, inclusion and excellence will extend the promise of America to succeeding generations. Our graduates will be the vanguard of leaders-committed to sustaining a democracy in which diverse people share in the rights and responsibilities of citizenship, proficient in applying technology to wise purposes, and dedicated to securing a humane world community and sustaining the bounty of the Earth.

\section{As an institution of higher learning:}

- We will create a community of shared values in which faculty, students, staff, administrators and alumni will experience personal satisfaction and pride in our collective achievements;

- We will be the first choice for university applicants who seek a rigorous, collaborative teaching/learning experience in a technologically rich environment;

- We will be the leader in enhancing the educational, cultural and economic resources of our region; and

- We will receive local and national recognition for our distinctive achievements in teaching, learnino. scholarshin and service. 


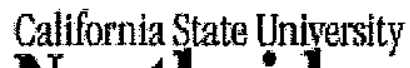 \\ Northridge}

\section{CORE VALUES IN ACTION}

Download Adobe Reader

Download Word Reader

\section{Responsibility}

As stewards of the University's human resources, we:

o treat staff and faculty fairly, with respect

- offer high quality, outcome-based services and programs

o support a culture of individual and group excellence

o invest in the professional development of staff and faculty

o demonstrate an inclusive, supportive, humane and healthy culture

o build positive relationships between all members of the campus community

\section{Community}

Our individual actions and collective responses determine our reputation on campus, in our professional associations, and in our neighborhood. We are a diverse team and we recognize the value of different perspectives. Our partnerships extend our positive influence.

\section{Integrity}

Our conduct conforms to the highest standards of the Human Resources profession.

Our dailv behavior and activities demonstrate respect for customers and for each other. 


\section{Quality}

The Office of Human Resources strives to meet or exceed the expectations of our university colleagues. We seek input from the campus community and embrace innovative improvements and creative solutions to our services, products and processes.

\section{Learning}

Our success as individuals, teams and as a University is enhanced by building our skills and competencies. We support and offer ongoing professional development. 


\section{GSI] The California State University}

MOHSHE FOH CALAF OHAYA

Home I Search

\section{The Mission of the California State University}

I. The mission of the California State University is:

- To advance and extend knowledge, learning, and culture, especially throughout California.

- To provide opportunities for individuals to develop intellectually, personally, and professionally.

- To prepare significant numbers of educated, responsible people to contribute to California's schools, economy, culture, and future.

- To encourage and provide access to an excellent education to all who are prepared for and wish to participate in collegiate study.

- To offer undergraduate and graduate instruction leading to bachelor's and higher degrees in the liberal arts and sciences, the applied fields, and the professions, including the doctoral degree when authorized.

- To prepare students for an international, multi-cultural society.

- To provide public services that enrich the university and its communities.

II. To accomplish its mission over time and under changing conditions, the California State University:

- Emphasizes quality in instruction.

- Provides an environment in which scholarship, research, creative, artistic, and professional activity are valued and supported.

- Stresses the importance of the liberal arts and sciences as the indispensable foundation of the baccalaureate degree.

- Requires of its bachelor's degree graduates breadth of understanding, depth of knowledge, and the acquisition of such skills as will allow them to be responsible citizens in a democracy.

- Requires of its advanced degree and credential recipients a depth of knowledge, completeness of understanding, and appreciation of excellence that enables them to contribute 
continuously to the advancement of their fields and professions.

- Seeks out individuals with collegiate promise who face cultural, geographical, physical, educational, financial, or personal barriers to assist them in advancing to the highest educational levels they can reach.

- Works in partnership with other California educational institutions to maximize educational opportunities for students.

- Serves communities as educational, public service, cultural, and artistic centers in ways appropriate to individual campus locations and emphases.

- Encourages campuses to embrace the culture and heritage of their surrounding regions as sources of individuality and strength.

- Recognizes and values the distinctive history, culture, and mission of each campus.

- Promotes an understanding and appreciation of the peoples, natural environment, cultures, economies, and diversity of the world.

- Encourages free scholarly inquiry and protects the University as a forum for the discussion and critical examination of ideas, findings, and conclusions.

- Offers degree programs in academic and applied areas that are responsive to the needs of the citizens of this state and provides for regular review of the nature and extent of these programs.

- Offers or proposes to offer instruction at the doctoral level jointly with the University of California and with private institutions of postsecondary education, or independently in the field of education where the need is clearly demonstrated. 